Contents List available at RAZI Publishing

https://doi.org/10.26480/esp.02.2017.01.03

\title{
MORINGA OLEIFERA AS COAGULANT USED IN WATER PURIFICATION PROCESS FOR CONSUMPTION
}

\author{
Jessica Tunggolou ${ }^{1 *}$, Carolyn Payus ${ }^{2}$

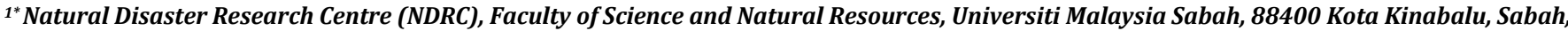 \\ Malaysia. \\ ${ }^{2}$ Water Research Unit (WRU), Faculty of Science and Natural Resources, Universiti Malaysia Sabah, 88400 Kota Kinabalu, Sabah, Malaysia. \\ *Corresponding Author Email: jessicarogertunggolou@yahoo.com
}

This is an open access article distributed under the Creative Commons Attribution License, which permits unrestricted use, distribution, and reproduction in any medium, provided the original work is properly cited

\section{ARTICLE DETAILS}

Article history:

Received 12 August 2016

Accepted 12 December 2016

Available online 7 November 2017

\section{Keywords:}

Moringa oleifera, Aluminum sulphate, Coagulation process, Turbidity, $\mathrm{pH}$, Conductivity

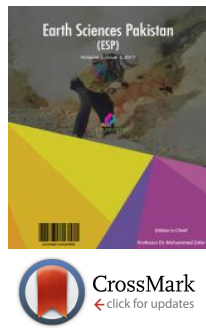

Water for consumption purpose needs to be treated to meet the quality guidelines of 5 Nephelometric Turbidity Unit (NTU) according to World Health Organization. The main objective of this study is to compare Moringa Oleifera Lam. to that of aluminum sulphate in terms of treatment efficiency. The method is carried out using Jar Tests and raw data are analyzed using Microsoft Excel Office Professional Plus 2013 and Pearson Correlation. Results shown proved the ability of Morina oleifera to remove the total suspended solids in the water from $35.9 \pm 1.65$ NTU to 3.17 $\pm 0.3 \mathrm{NTU}$ at optimum dosage of $15 \mathrm{mg} / \mathrm{l}$ while aluminum sulphate to $7.26 \pm 2.13 \mathrm{NTU}$ at dosage of $55 \mathrm{mg} / \mathrm{l}$. The treatment efficiency of Moringa oleifera is also higher at $91.17 \%$ and aluminum sulphate is at $78.72 \%$. Moringa oleifera resist changes in $\mathrm{pH}$ as final reading of the water sample increases from $5.67 \pm 0.23$ to $6.05 \pm 0.03$ while aluminum sulphate decreases to $3.43 \pm 0.05$ which indicates elevated acidity level. Conductivity reading of $M o r i n g a$ oleifera is constant at range of $113.33 \pm 5.77 \mathrm{lLS}$ while aluminum sulphate increased drastically from initial reading of $86.67 \pm 5.77 \mathrm{lLS}$ to $1120 \pm 10.0 \mathrm{lLS}$. The final temperature is still at normal room temperature range after the addition of both coagulants at $22.07^{\circ} \mathrm{C}$ to $24.97{ }^{\circ} \mathrm{C}$. As a conclusion, a cheaper and safer coagulant such as Moringa oleifera as compared to aluminum sulphate can be established.

\section{INTRODUCTION}

$75 \%$ out of the total number of world population was roughly estimated to still live in developing countries and 1.2 billion is still lacking safe drinking water supply. Another 6 million children were also estimated to die from diarrhoea each year in developing country [1]. This data shows that lacking basic clean water supply is a huge concern that must be dealt with in developing countries since they seem incapable of supplying the citizens with water that satisfy drinking water guidelines. Kalbamatten and Burns in their research has stated the consequences of poorly treated water which resulted from the lacking water treatment facilities kills people every day while others suffer from the side effects [1] due to the waterborne diseases caused by the pathogenic micro-organisms such as protozoa, viruses, bacteria, and intestinal parasites from the consumption of the contaminated water thus making water purification process a must before it is considered as safe for consumption. Due to these cases, water for drinking needs to be treated in order to meet the quality guidelines which satisfy 5 NTU for drinking water requirement according to WHO (2006) [2]. In the latest water treatment technology, chemical such as aluminum sulphate was used in the water purification process. According to Schulz and Okun [3], those treatment agents are mostly imported and not to mention expensive as well. Aluminum sulphate needs $\mathrm{pH}$ adjustment when used in the treatment process which is regarded as another additional cost for water treatment companies [1] As stated in Martyn et al. [1], naturally occurred coagulants are regarded as safe in terms of health for human while synthetic coagulants, especially aluminum salt, has probability inducing Alzheimer's disease. GarciaFoyas et al. [4] has supported this case where increasing health risks such as neurodegenerative illness was mentioned from consuming the water with residual aluminum left in it. Other than proposed to have higher turbidity removal compared to aluminum sulphate, Moringa oleifera also possessed numerous health benefits such as anti-ulcer, hepatoprotective, anti-bacterial, anti-fungal, anti-hypertensive, anti-tumor, anti-cancer activities, and not to mention, diuretic and cholesterol lowering activities [5]. Hence to solve the problem that has been stated, Moringa oleifera can be used as an alternative to replace synthetic aluminum sulphate for better turbidity removal and also for safe consumption for human. This study thus, was intended to compare the efficiency of seed extracts of Moringa oleifera and aluminum sulphate in treating water that is used for consumption.

\section{MATERIAL AND METHODS}

This study was conducted from May 2016 to May 2017 at Universiti Malaysia Sabah (UMS) Environmental Science laboratory.

\subsection{Preparation of coagulants}

Two types of coagulants used in this study are Moringa oleifera seeds (naturally occurring coagulant) and aluminum sulphate (laboratory grade) (synthetic coagulant). The Moringa oleifera seeds were air-dried at $40^{\circ} \mathrm{C}$ for two days. The seeds were removed manually from the seed coats and is grounded using basic pestle and mortar (PPM125) to turn them into powder form. The same method was applied to aluminium sulphate where it was grounded to powder using pestle and mortar.

\subsection{Preparation of water sample}

Water sample used was collected from well in Kampung Gaur located in Kota Belud district, Sabah where the rural people living near the source used it as an actual drinking water source.

\subsection{Jar tests study}

The jar test was carried out using Junke and Kunkel jar test (Lovibond ET 730). The parameters were tested before and after the treatment given. Different coagulant amount was also added to the water sample to be tested. After the addition of the coagulant, the water was mixed rapidly using $125 \mathrm{rpm}$ for 5 minutes, and then slowed down to $50 \mathrm{rpm}$ for 30 minutes. It was then left undisturbed to settle for 1 hour. After the settlement of the water treatment, the water was taken and measured. 
Four parameters were tested in this such as turbidity, $\mathrm{pH}$, conductivity and temperature. Turbidity was tested using turbidity meter (HACH 2100P), $\mathrm{pH}$ was tested using $\mathrm{pH}$ meter (Digimed DM-2), conductivity using conductivity meter (EC 500) and temperature using basic thermometer. Raw data obtained from the experiments will be used in the analysis to ensure that Moringa oleifera used in the water treatment system is in the range of the water quality for safe drinking water consumption.

\subsection{Analysis}

Microsoft Excel Office Professional Plus 2013 and Pearson Correlation were used to analyze the data obtained from the study. The $\mathrm{P}$ value was also determined to show if there was a significant difference with either $(\mathrm{P}>0.05)[6]$.

\section{RESULTS AND DISCUSSION}

\subsection{Turbidity}

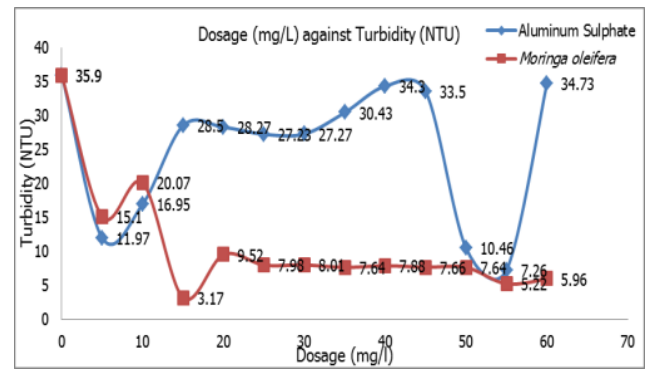

Figure 1: The graph shows the comparison of dosage (mg/l) against turbidity (NTU) for both coagulants used

The colloidal stability owes its property to their static electricity and hence, with coagulant addition that carries positive charges to the water, destabilization of the colloidal in the water occurs and the negative charges on the colloidal are disrupted making the coagulation of the particles possible [7], thus creating the pattern as shown in the graph. The most important finding of utilizing Moringa oleifera as coagulant is the reduction from initial reading of turbidity at $15 \mathrm{mg} / \mathrm{l}$ where the lowest turbidity was achieved even with smaller doses used compared to aluminum sulphate at $55 \mathrm{mg} / \mathrm{l}$. Both of the coagulants showed similar patterns for reduction as they were seen to increase and decrease continuously which shows that both of them used adsorption and neutralization process to neutralize the charges on the colloidal and therefore showing identical trend of increase in turbidity when overdosing occurred as well. The effects of dosage have on turbidity has been highlighted by [8]. When aluminum sulphate was used as coagulant, the highest percentage of removal of the turbidity is $78.72 \%$, while using Moringa oleifera, the highest percentage of removal of the turbidity is $91.17 \%$. Aluminum sulphate mechanism is explained as such; addition of the coagulant to water rapidly hydrolysed the salts producing cationic species responsible for absorbing negatively charged particles of the colloidal and also for neutralizing their charge. Destabilization of the particles then can take place [8]. As for mechanism of Moringa oleifera for the turbidity reduction by Jahn, as cited in [10], it is mostly due to the seed proteins.

\section{$3.2 \mathrm{pH}$}

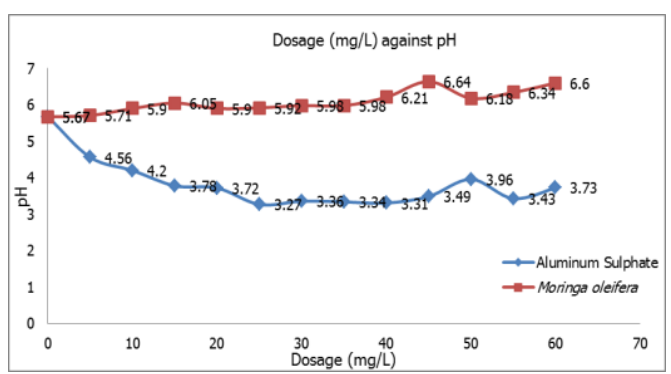

Figure 2: The graph shows the comparison of dosage (mg/l) against $\mathrm{pH}$ for both coagulants used

In the usage of aluminum sulphate as coagulant, the initial groundwater $\mathrm{pH}$ turns more acidic while using Moringa oleifera as coagulant reading remains constant. Permitted limit of World Health Organization (WHO) standard for drinking water is 6.0-8.5 and the use of Moringa oleifera caused the final $\mathrm{pH}$ reading being in the permitted range of standard for drinking water. Since coagulants have their own respective optimal range of $\mathrm{pH}$ that affects the efficiency of their actions, it is an important parameter to be taken into consideration [11]. The aluminum sulphate final $\mathrm{pH}$ reading is below the accepted range of drinking water due to the action of coagulant consuming their alkalinity during the hydrolysis. This is consistent with the results obtained from Sahu \& Chaudhari [12] where they stated that since aluminum sulphate is more acidic, this leads to higher consumption of alkalinity of the coagulant in order to prevent the water to become acidic. Sasikala \& Muthuraman [13] mentioned in their study that Moringa oleifera coagulation efficiency is particularly good at $\mathrm{pH}$ acidic which is at less than 6 and also $\mathrm{pH}$ that is greater than 11 dues to the influence of positive charges on the amino acids that builds up the protein molecule. Both coagulants trend of reduction was seen to increased and decreased constantly due to the hydrolysis where the hydrogen ions are balancing out the hydroxide ions for both of the coagulants [9]. But nevertheless, the most important finding is aluminum sulphate usage was seen to lower the $\mathrm{pH}$ of the groundwater sample to acidic, while for the usage of Moringa oleifera as caogulant is that they do not cause water to turn acidic as compared to when aluminium sulphate was used.

\subsection{Conductivity}

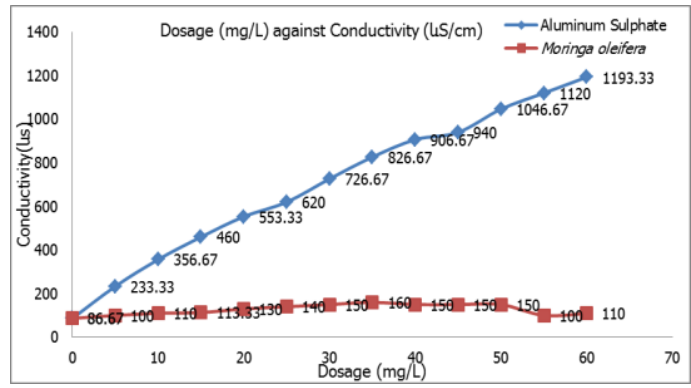

Figure 3: The graph shows the comparison of dosage (mg/l) against Conductivity (LS) for both coagulants used

The trend of the initial conductivity of the groundwater sample was seen to increased significantly after the addition of aluminum sulphate but however when Moringa oleifera was used, there is only a little increase in the conductivity reading. Since the permitted limit of conductivity allowed by World Health Organization (WHO) for drinking water is 0 $3000 \mathrm{LS}$, both of the coagulants used are still in the range. Both of the coagulants, aluminum sulphate and Moringa oleifera show similar trend of increasing conductivity. Increase in the conductivity reading was expected as ions are formed during the coagulation process and these ions contributed to the overall conductivity [12]. Hence higher coagulant dosage will finally result in the conductivity reading being higher as observed. Usage of aluminum sulphate increased the conductivity reading as the effects of the water reaction with acidic or alkaline metals. The conductivity value is also dependent on ions concentration in the water [14]. When Moringa oleifera was used, the results revealed that the use of excess Moringa oleifera above the optimum dosage results in the increase in the conductivity reading again believed to be caused by the unbound ions that present in the water [14]. Overall in the present research, Moringa oleifera coagulation process only has little influence on the degree of conductivity as they reacted as positively charged natural polymer coagulant.

\subsection{Temperature}

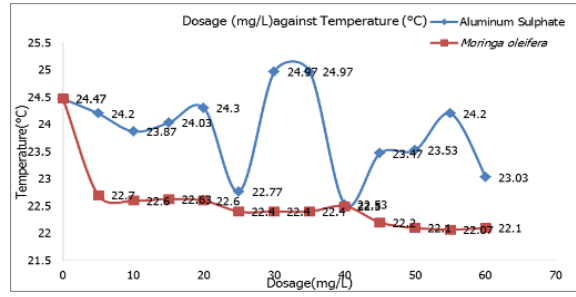

Figure 4: The graph shows the comparison of dosage (mg/l) against Temperature $\left({ }^{\circ} \mathrm{C}\right)$ for both coagulants used.

The initial temperature of the groundwater was $24.47^{\circ} \mathrm{C}$ and the highest temperature after the addition of aluminium sulphate is $24.97^{\circ} \mathrm{C}$ while for Moringa oleifera is $22.7^{\circ} \mathrm{C}$. Both of the final temperatures after the addition of the coagulants used are in the limit of room temperature 
range. This is in line with the study from Hendrawati et al., [14] where in the research, the addition of Moringa oleifera in the water purification only reached $29.00^{\circ} \mathrm{C}$ at their highest from initial reading of $28.40^{\circ} \mathrm{C}$. Thus, it was concluded in the study that the use of the coagulant in the process does not affect the water temperature drastically as their temperature is still in the normal range for water. León-Luque et al., [11] has also found that water with lower temperature affects the coagulation efficiency rate as it is usually longer for the flocculation to takes place. A study by Othman et al., [15] shows Moringa oleifera coagulation effciency decreased when temperature of the wastewater was increased from $30^{\circ} \mathrm{C}$ to $70^{\circ} \mathrm{C}$. The reason to this is most probably caused by charge destabilization of the suspended solids in the wastewater. Similar study performed by Fitria et al., [16] also explored the temperature effects at $20^{\circ} \mathrm{C}$ and $26^{\circ} \mathrm{C}$ using Moringa oleifera as coagulant and has found it works better at $26^{\circ} \mathrm{C}$ rather than at $20^{\circ} \mathrm{C}$. It was most probably due to Moringa oleifera proteins being more active at higher temperatures. Different findings reported different results as there are no fixed or constant temperature that the coagulants are said to be most effective. But however, in this case study, the initial water temperature of $24.47^{\circ} \mathrm{C}$ clearly is more favourable for Moringa oleifera as their efficiency rate is higher at their optimum dosage by comparing the coagulation efficiency of aluminum sulphate and Moringa oleifera.

\section{CONCLUSION}

The finding from the study shows seed extracts of Moringa oleifera was very effective as coagulants in removing turbidity in the groundwater sample. The results from the study revealed optimum dosage to treat the well water sample was $15 \mathrm{mg} / \mathrm{l}$ for Moringa oleifera and $55 \mathrm{mg} / \mathrm{l}$ for Aluminium sulphate with both having $91.17 \%$ and $78.72 \%$ of turbidity removal respectively. Other significant finding from this study revealed that Moringa oleifera as coagulant did not affect $\mathrm{pH}$ of water samples unlike alum. Moringa oleifera can meet the requirements of drinking water quality for rural area household water treatment with further optimization.

\section{ACKNOWLEDGEMENT}

Through this research, the authors gratefully acknowledge the financial support of the University of Malaysia Sabah (UMS) Grant through (GUGU0026-STWN-M-1/2016) and all those who have directly or indirectly contributed during the process of writing and publishing of this study.

\section{REFERENCES}

[1] Ali, E.N., Muyibi, S.A., Salleh, H.M., Salleh, R.M., and Alam, Z. 2009. Moringa oleifera seeds as natural coagulant for water treatment. Thirteenth International Water Technology Conference, IWTC 13, Hurghada, Egypt, 163-168.

[2] World Health Organization. 2006. Guideline for drinking-water quality (electronic resources): incorporating first addendum. Volume 1, Recommendations, $3^{\text {rd }}$ edition.

[3] Yusuf, J., Yuakubu, M.B., and Balarabe, A.M. 2015. The use of Moringa oleifera seed as a coagulant for domestic water purification. IOSR Journal of Pharmacy and Biological Sciences, 10 (1), 06-09.

[4] Egbuikwem, P.N., and Sangodoyin, A.Y. 2013. Coagulation efficiency of Moringa oleifera seed extract compared to Alum for removal of turbidity and E. coli in three different water sources. European International Journal of Science and Technology, 2 (7), 13-20.

[5] Anwar, F., Latif, S., Ashraf, M., and Gilani, A.H. 2007. Moringa oleifera: A Food Plant with Multiple Medicinal Uses. Phytotherapy Research, 21 (1), 17-25.

[6] Vieira, A.M.S., Vieira, M.F., Silva, G.F., Araujo, A.A, Fagundes, M.R., Veit, M.T, and Bergamasco, R. 2010. Use of Moringa oleifera seed as a natural adsorbent for Wastewater Treatment. Water Air Soil Pollution, $206(1-4), 273-281$.

[7] Postolachi, L., Rusu, V., Lupascu, T., and Maftuleac, A. 2015. Improvement of coagulation process for the Prut River water treatment using aluminium sulphate. Chemistry Journal of Moldova. General Industrial and Ecological Chemistry, 10 (1),25-32.

[8] Zad, A.D., and Hoveidi, H. 2015. Aluminium Sulphate and PolyAluminium Chloride (PAC) performance in turbidity removal from synthetic water. Journal of Applied Biotechnology Reports, 2 (3), 2423 5784 .

[9] Megersa, M., Beyene, A., Ambelu, A., Asnake, D., Bekele, T., Firdissa B., Alebachew, Z., and Triest, L. 2016. A preliminary evaluation of locally used plant coagulants for household water treatment. Water Conservation Science and Engineering, 1 (2), 95-102.

[10] Ndabigengesere, A., Narasiah, K. S., and Talbot B. G. 1995. Active agents and mechanism of coagulation of turbid waters using Moringa oleifera. Water Research, 29 (2), 703-710.

[11] León-Luque, A. J., Barajas, C.L., and Peña-Guzmán, C. A. 2016. Determination of the optimal dosage of Aluminum Sulfate in the coagulation-flocculation process using an artificial neural network. International Journal of Environmental Science and Development, 7 (5), 346-350.

[12] Jowa, T., and Mguni, L.L. 2015. Treatment of low turbidity water using Poly-Aluminium Chloride (PAC) and Recycled Sludged: Case study Chinhoyi. Zimbabwe Journal of Science and Technology, 101-108.

[13] Sasikala, S., and Muthuraman, G. 2016. A laboratory study for the treatment of turbidity and total hardness bearing synthetic wastewater/ground water using Moringa oleifera. Industrial Chemistry, 2 (1).

[14] Hendrawati, Yuliastri, I.R., Nurhasni, Rohaeti, E., Effendi, H. and Darusman, L.K., $2016 . \quad$ The use of Moringa oleifera seed powder as coagulant to improve the quality of Wastewater and Ground Water. IOP Conference Series: Earth and Environmental Science, 31, 012-033.

[15] Othman, Z., Bhatia, S., and Ahmad, A.L. 2008. Influence of the settle ability parameters for Palm Oil Mill Effluent (POME) pre-treatment by using Moringa oleifera seeds as an environmental friendly coagulant. International Conference on Environment (ICENV).

[16] Fitria, D., Scholz, M., Swift, G.M., and Hutchinson, S.M. 2014. Impact of sludge floc size and water composition on sludge dewaterability. Chemical Engineering and Technology Journal, 37 (3), 471-477. DOI: 10.1002/ceat.201300378. 